Témoigner Témoigner. Entre histoire et mémoire

Getuigen Revue pluridisciplinaire de la Fondation Auschwitz

$123 \mid 2016$

Traduire le témoignage

\title{
Saul Fia / Son Of Saul, de doden spreken
}

Saul Fia / Son of Saul / Le fils de Saul, paroles de morts

\section{Erik Machielsen}

Traducteur : Gorik de Henau

\section{(2) OpenEdition}

\section{Journals}

Édition électronique

URL : https://journals.openedition.org/temoigner/5044

DOI : 10.4000/temoigner.5044

ISSN : 2506-6390

Éditeur :

Éditions du Centre d'études et de documentation Mémoire d'Auschwitz, Éditions Kimé

Édition imprimée

Date de publication : 1 octobre 2016

Pagination : 5-8

ISBN : 987 2-9600926-4-6

ISSN : 2037-4183

Référence électronique

Erik Machielsen, «Saul Fia / Son Of Saul, de doden spreken», Témoigner. Entre histoire et mémoire

[Online], 123 | 2016, Online op 02 novembre 2021, geraadpleegd op 04 novembre 2021. URL: http:// journals.openedition.org/temoigner/5044 ; DOI: https://doi.org/10.4000/temoigner.5044

Tous droits réservés 


\section{SAUL FIA / SON OF SAUL DE DODEN SPREKEN}

FILM Kun je de huiver van Auschwitz vertalen in een fictiefilm? Het antwoord luidt positief. Het pijnlijke maar krachtige bewijs daarvan wordt geleverd door Son of Saul.

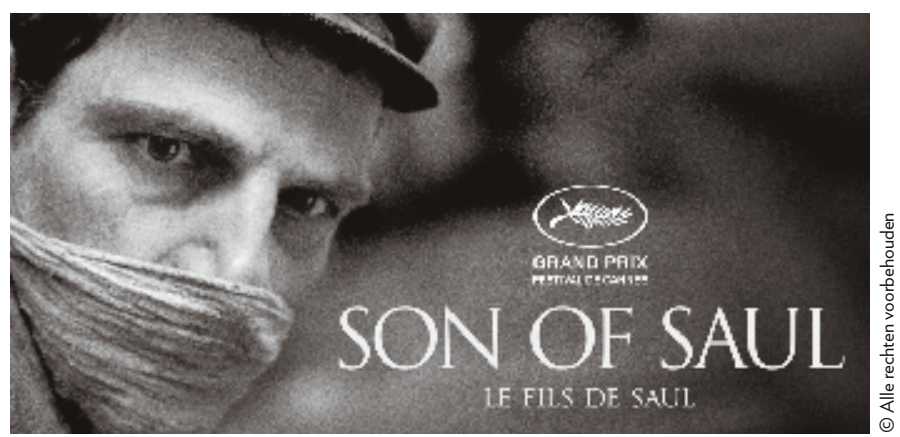

A uschwitz-Birkenau, oktober 1944. Een ondoordringbaar gezicht met op elkaar geklemdekaken, opgesloten in het benauwde beeldkader... Het behoort toe aan Saul Ausländer, een lid van het Sonderkommando, de eenheid van Joodse gevangenen die de nazi's moeten bijstaan bij hun laaghartige bezigheden. Dag en nacht staan ze in voor het goed functioneren van de moordmachine in het hart van de Holocaust: ze leiden de naakte mensenmassa naar de gaskamers, bergen en verbranden de lijken, en verspreiden de assen. Daarna zullen ook zij sterven.

Op die bewuste dag meent Saul tussen de opgehoopte lichamen zijn zoon te herkennen. Met gevaar voor eigen leven kent hij voortaan maar één zorg meer, namelijk de jongeman een waardig graf bezorgen en hem begraven overeenkomstig de gebruiken van zijn religie. De geremde en getraumatiseerde Saul wordt ongevoelig voor zijn omgeving, verliest maat voor de dingen, verschanst zich in zijn wereld. Hij bouwt voor zichzelf een gevangenis waarvan hij de sleutel weggooit - een gevangenis waarin hij ook ons opsluit.

We worden dan wel overdonderd door het ritme en de geluidsband, toch stellen we ons vragen bij sommige situaties, bij de houding van die haast suïcidale man die er niet voor terugdeinst om ook zijn lotgenoten in gevaar te brengen. We vragen ons zelfs af of het stoffelijk overschot dat hij rondzeult wel van zijn zoon is. Misschien is hij krankzinnig geworden door het verdriet om het verlies van zijn kind en de wanhoop die daar het gevolg van is. Dat is een mogelijke verklaring, een vorm van twijfel die de regisseur in de slotsequentie opwerpt.

Duidelijk is wel dat we hier mijlenver verwijderd zijn van de onderhoudende, avontuurlijke spektakelcinema van Steven Spielberg, hoe lovenswaardig diens intenties ook mogen geweest zijn. Saul is gelaten en afgemat; hij is een slachtoffer dat gebukt gaat onder het lijden. Vanaf het begin is hij niet langer een mens, maar een zombie, een robot die ronddwaalt door een permanente chaos. Hij is nergens meer bang voor, en wel hierom: hij heeft een punt bereikt van waaruit geen terugkeer mogelijk is. Het enige wat nog telt, is de belofte die hij aan zichzelf heeft gedaan. Hij wordt ongevoelig voor anderen, sluit zich op in zijn cocon, is zich niet bewust van de gevolgen van zijn houding en koestert onterechte verdenkingen. Hij klampt zich wanhopig vast aan illusies en zet zelfs oogkleppen op als hij een man ontmoet die zich voor rabbijn uitgeeft om zijn hachje te redden.

\section{BEKROONDE WAARHEID}

Son of Saul werd bekroond met meer dan veertig onderscheidingen, onder meer de grote prijs op het 68ste festival van Cannes en de Golden Globe voor de beste buitenlandse film in 2016. België bleef niet achter, want in januari van dit jaar kende de Unie van de Belgische Filmpers (UBFP) de film haar Grote Prijs toe, een maand vóór de opperste bekroning, namelijk de Oscar voor de beste buitenlandse film. Het is trouwens $\bullet \bullet$ 
œ de zesde film over de Holocaust die deze prijs wint. De vorige vijf waren: Obchod na korze van Ján Kadár en (1971), Lavità bellhvan Roberto Begi(1998), Die Fölscher Laviè bellavan Roberto (Begnin (1998), Die Fulscher van Stefan Ruzowitzky (2007) en lda van Pawet Pawlkowsi (2014). We vermelden nog enand niet nag Cannos hij 'PTix Vulcain d'artiste technicien' Cannes won hijde 'Prix Vulcaindelartiste technicien' anwege cilmvertelling' We kunnen het zelf nietband uitdrukken.

HONGAARSE ODYSSEE

In 2016 is László Nemes 39 jaar oud. Op het ogenblik van de feiten was hij dus nog niet geboren, maa hij verloor wel een deel van zijn familie in Auschwitz. hij prijen in zijn eerste lange speelfilm. In 2007 won hij prijzen in Lissabon, Angers en Bilbao met Turelem (With a Little Patience), een korte film van 14 minuten. De prijs die hij in Boedapest wint, gaat vergezeld va het commentar 'voor de ongewone behandeling van eer o haal speelt zich al af in een kanp, maar bovenal is er de camera die scherpstelt op het gezicht van een jonge rouw - rond har blijt al es wazig. De film heeft geen dialogen, alleen geluid engeluidsefecten. Innavolging van zijn m stijl waarmee hij zich van zijn collega's onderscheidt.

\section{SAULS ZIEL}

Een van de sterke punten van de film is dat we de acteurs niet kennen - wat in commercieel opzicht een handicap had kunnen zijn. We zien het personage, niet de acteur die het vertolkt, en dat blijkt een voordeel. Die acteur is Géza Röhrig.

In de steek worden gelaten, eenzaamheid, isolement: hij kan ervan meespreken. Zijn moeder geeft hem op, hij wordt grootgebracht in een weeshuis, op vierjarige leeftijd verliest hij zijn vader en op zijn twaalfde wordt hij geadopteerd door een joods gezin waarvan sommige leden in Auschwitz werden vermoord. Na een bezoek aan het kamp begint hij de joodse voorschriften na te leven. Dat bezoek moestéén dag duren. Hij is zodanig onder de indruk van wat hij ziet dat hij een maand ter plaatse blijft om te mediteren en na te denken
Hij studeert af aan de hogeschool voor toneel en film in Boedapest, waar hij les krijgt van onder anderen bí de regisseur van Mephisto. Dankzij die film werd Klaus Maria Brandauer bekend, maar het was vooral de eerste Hongaarse productie die werd 作 in 1982. De tweede is... Son of Saul. Maar Röhrig laat ich in de eerste plaats toch opmerken als schrijver en vooral dichter. In 1995 verschijnt zijn eerste publicatie, namelijk door de Holocaust geïnspireerde gedichten. ijn ervaring als acteur beperkt zich vooralsnog to een handvol televisieoptredens eind jaren tachtig. In de jaren 2000 heeft László Nemes een ontmoeting met Röhrig in diens woonplaats New York. Ze ontdekken dat ze gemeenschappelijke interesses hebben en worden vrienden. Son of Saul is Röhrigs eerste lange speelfilm Aangezien de toeschouwer er al niet zonder kleerscheuren uitkomt, kun je je wel voorstellen hoe gevaarlijk die ervaring voor hem moet zijn geweest - maar hij word er wel op diverse festivals voor bekroond

ONTSTAANSGESCHIEDENIS

In 2011 schrijft László Nemes in Parijs - hij spreekt vloeiend Frans - het scenario van zijn film, samen met Clara Royer. DeFranse auteur-scenarist van Hongaarse akomst werd bekend met Csillag, haar eerste roman waarin de heldin een identiteitscrisis doormaakt en op zoek gaat naar haar afkomst. Son of Saul staat in de beurde feiten opgetekend in hetboek $D$ es voir waargebeurde (eiten, opgeteken het of Aus $h$ ix sous la cendre (eerste uitgave: The Scrolls of Auschwitz, 1985). In dat collectieve werk werden drie van de vijf geschriften Birkenau onder de grond verstopten; ze werden tussen Dat de flerichevonden.

Dat de film zich op eén enkel personage concentreert, verwijst naar een andere oorlogsfilm. In het Russische Idi i smotri/Kom en zie (1985) gebruikt Elem Klinov ook long takes en - in de plaats van dialogen te te geven aan de angst, de beklemming, de dood die ell Tot

Tot slot is Son of Saul ook het resultaat van vier jaar diepgravend onderzoek. Zoveel tijd hadden Nemes en Royer nodig om documentatiemateriaal te verzamelen en een aantal mensen te ontmoeten, onder anderen getuigensc geschiedkundige Gideon Greif, die ove getuigenissen van
den beschikte.

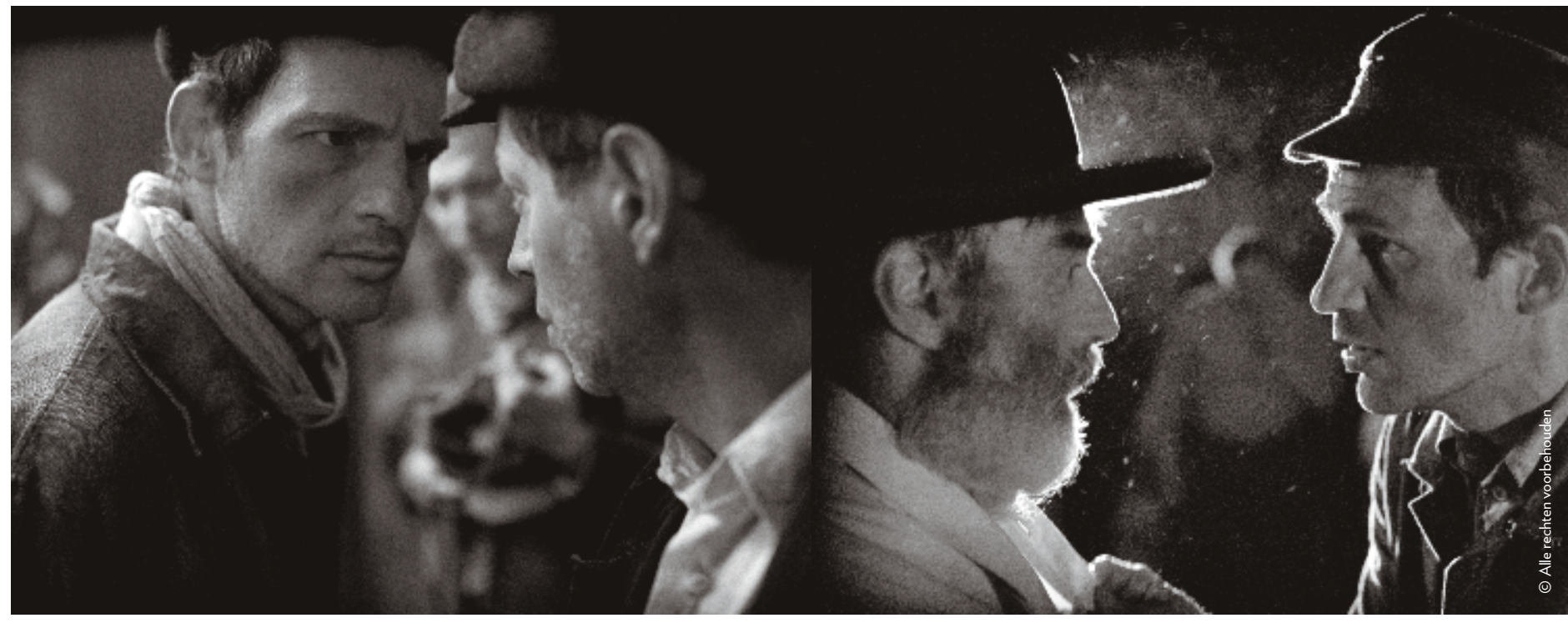

DILEMMA 1

Een aparte aanpak wordt vaak verworpen en dat aparte karakter schuilt ditmaal in de vorm. Daarom is eengeb een gebruiksaanw lend is voor het effect on lend is voor het effect, ook en vooral als je er niet mee ertor personge, de. aandacht krijgt. Door zijn verdriet heeft Saul een gren hij de gruwelin de ans likt te on zone de

\section{DILEMMA 2}

Son of Saul behoort ook tot de soort films die verbluffen of waar je een hekel aan hebt. Of waar je minstens wantrouwig tegenover staat. Frankrijk, Israeel, Duitsland or Oostenijk: nergens wilden ze met geld over de brug komen, wegens te ontoegankelijk. Want Nemes blaast do codes op. Hoowd dim fraai gefoto-

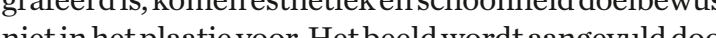
niet in het plaatje voor. Het beeldwordt aangevuld doo wel het velijk nog explcietere wel het verhal on vantshappen aan. Dat stemt overeen met het gevoel van de regisseur dat je uit Auschitz onmogelijk kunt hier hetwo geft, weten dat mar, an regisseur er toch in slaagde het budget van 1,6 miljoen dollar bij elkaar te brengen dankt hij in de eerste plaats an het Hongaars Filmfonds.

Afgaand op de talrijke onderscheidingen is het wemes geslaagd. Maar de meeste daar-

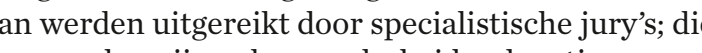
te Er zullen dus altijd mensen zijn die been deel van uit. prijzen wus altijd mensen zijndie beweren dat al die prijzen werden toegekend om andere dan filmische

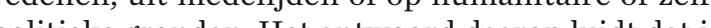
politieke gronden. Het antwoord daarop luidt dat $j e$ een dernate doordachte flm niet onvoorbereid kun benaden. Dar het tijd heeftgek oston hen te maken is het normaal dat het tijd kost om hem te begrijpen, hij tot stand kwa juiste redenen, namelijk die waarom hij tot stand kwam. Best mogelijk dus dat je hem bijeen inste visie vreselijk of zelfs mislukt vindt, en bij nader ring als reactie op de vorm.

DILEMMA

Kortom, dat sommigen het niet op die vorm hebben begrepen is hun goed recht. Maar niemand kan onverchillig blijven voor de kern van de zaak, namelijk de hel van Auschwitz-Birkenau. In dat verband is de film exenplarisch, dankzijeendoorged 


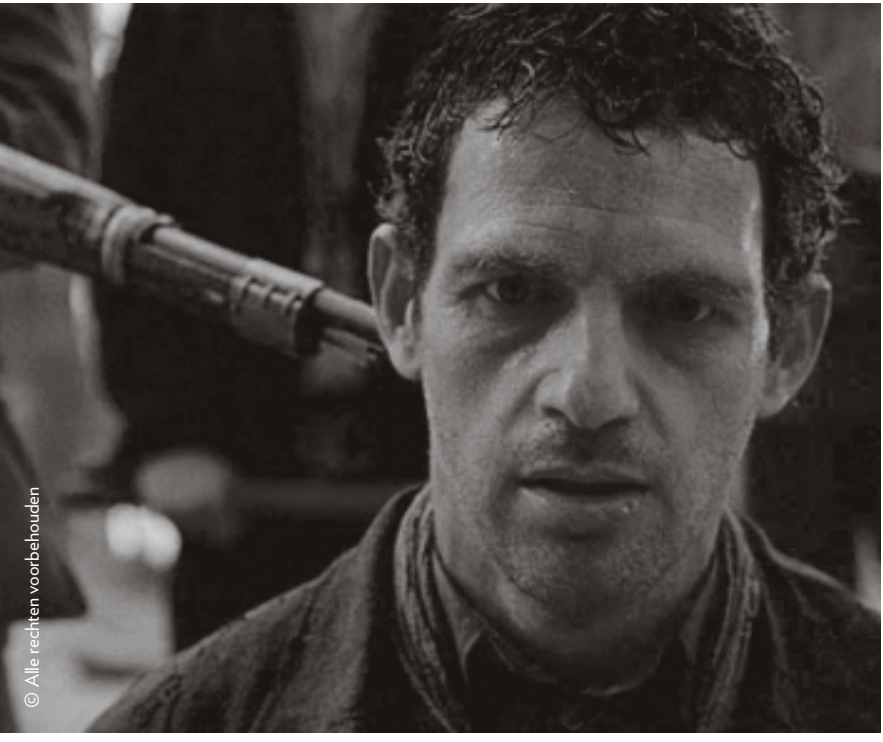

••van kreten, knarsende deuren, knallende geweerschoten. Dit alles draagt bij tot de beklemmende sfeer, waardoor je in de war wordt gebracht, het benauwd krijgt en je ongemakkelijk gaat voelen. Was het echt nodig een viscerale film te construeren en de toeschouwers bewust te maken door hen te verplichten aldoor naar een dwingende grootopname te kijken? Ja, want op die manier is er niet langer sprake van eenvoudigweg kijken, maar van onderdompeling. Een onderdompeling die zodanig traumatiserend werkt dat we de film afraden voor overmatig emotionele, ontvankelijke of gevoelige personen.

Maar overdrijven is nooit goed. Je mag er geen systeem van maken om de camera vast te klinken aan het gezicht van de protagonist en schroeiend intense cinema te bedrijven in de stijl van de gebroeders Dardenne. Nemes zou zo heel snel terechtkomen in het vakje 'heb je er één gezien, dan heb je ze allemaal gezien'. Daarom kijken we met een zekere nervositeit uit naar zijn volgende film, weer in samenwerking met Clara Royer. De titel is nog niet bekend, maar het wordt een thriller, opnieuw gebaseerd op het onderdompelingsprincipe en ditmaal vertrekkend van een vrouw.

\section{EEN ZOON VAN LANZMANN}

Als het over een werkstuk aangaande de Holocaust gaat, ligt meteen de vergelijking met Shoah (1985) voor de hand, de meer dan tien uur durende docu- mentaire die ter zake de standaard is geworden. En Claude Lanzmann, de regisseur, wordt geregeld om zijn mening gevraagd. Zonder ooit geringschattend te worden - zich met de Holocaust bezighouden dwingt sowieso respect af - was hij tot dusver van mening dat het Holocaustdrama voor veel regisseurs niet meer was dan een decor dat ze konden gebruiken om er hun eigen stempel op te drukken, en dit geldt ook voor Spielberg en diens Schindler's List. Je zag de kampen wel, maar je wás er niet. Tot Lanzmann op het voorlaatste festival van Cannes Son of Saul zag. Hij was gaan kijken op basis van de groeiende reputatie van de film, maar met een zekere terughoudendheid. Hij kwam helemaal overtuigd naar buiten en verklaarde: 'Alleen fictiefilm is even waarachtig als Shoah. Voor mij is Son of Saul van hetzelfde niveau.' En in één ruk door ridderde hij de regisseur door hem zijn artistieke zoon te noemen.

Dat iemand van het kaliber van Lanzmann de film hoog aanslaat, kan dus helpen om het grote publiek over de streep te trekken. Evenmin klinkt het goedkoop te stellen dat Son of Saul, net als Shoah, symbolische waarde heeft. De plicht om niet te vergeten blijft dezelfde, maar het register verschilt: van contemplatie - al kan die term onhandig lijken - zijn we overgegaan naar onderdompeling. En dat Son of Saul het geesteskind is van erfgenamen van de Holocaust, en niet van tijdgenoten, maakt een en ander nog betekenisvoller.

\section{NIET TE MISSEN}

Veel mensen hebben nog geen lessen getrokken uit de genocide, barbarij bestaat nog altijd. In dat opzicht is Son of Saul heilzaam, want hij vormt er een bolwerk tegen. Ga kijken, en bij voorkeur in een bioscoop met een degelijke geluidsinstallatie; de film in de huiskamer op dvd zien heeft geen enkele zin.

Erik Machielsen Vertaling: Gorik de Henau

\footnotetext{
Meer weten Saul fia/Son of Saul van László Nemes (2015).

Met Géza Röhrig (Saul Ausländer), Levente Molnár (Abraham Warszawski), Urs Rechn (Oberkapo Biederman), e.a. 107 minuten.

$\Leftrightarrow$ Lees ook het interview met Gideon Greif, auteur van We Wept without Tears: Testimonies of the Jewish Sonderkommando from Auschwitz, verderop in dit nummer.
} 